\title{
Pengenalan Ikan Hias Laut Pada Anak Usia 3 Tahun Dengan Metode Marker Based Tracking Berbasis Augmented Reality \\ Apriliani Wulandari ${ }^{1}$, Septi Andryana ${ }^{2}$, Aris Gunaryati ${ }^{3}$ \\ 1,2,3 Fakultas Teknologi Komunikasi dan Informatika, Universitas Nasional e-mail: *1aprilianiwulan10@gmail.com, ${ }^{2}$ septi.andryana@civitas.unas.ac.id, \\ 3aris.gunaryati@civitas.unas.ac.id
}

\begin{abstract}
ABSTRAK - Keanekaragaman hewan di Indonesia sudah dikenal hingga mancanegara. Indonesia memiliki berbagai spesies hewan baik di darat maupun di laut. Keberadaan hewan laut di Indonesia saat ini semakin terancam dengan adanya kerusakan ekosistem laut dan perburuan liar pada hewan laut. Teknologi informasi saat ini banyak sekali yang bisa di jadikan sebagai media pembelajaran terhadap anak salah satunya Augmented Reality. Augmented Reality ini dapat di manfaatkan sebagai media pengenalan ikan hias yang ada di laut dalam bentuk 3D dengan menggunakan metode marker based tracking. Dengan Augmented Reality ini anak-anak dapat mengenal hewanhewan yang ada di dalam laut dan dapat merangsang minat belajar dan imajinasi pada anak. Dari hasil pengujian sudut yang dilakukan hasil dari ketiga smartphone yaitu pada sudut $21^{\circ}-90^{\circ}$ dapat terbaca sedangkan untuk sudut $<15^{\circ}$ AR tidak dapat timbul sebab marker tidak terbaca oleh kamera.
\end{abstract}

Kata Kunci: Augmented Reality, Ikan Hias Laut, Marker Based Tracking, Pengenalan

ABSTRACT - Animal diversity in Indonesia is well known to foreign countries. Indonesia has a variety of animal species both on land and at sea. The presence of marine animals in Indonesia is currently increasingly threatened by the destruction of marine ecosystems and poaching in marine animals. Information technology at this time a lot that can be made as a medium of learning for children one of which is Augmented Reality. This augmented reality can be utilized as an introduction to ornamental fish in the sea in 3D using the marker based tracking method. With this Augmented Reality, it is hoped that children can get to know animals in the sea and can stimulate children's learning and imagination. From the results of angle testing, the results of the three smartphones, namely at an angle of $21^{\circ}-90^{\circ}$ can be read while for angles $<15^{\circ}$ AR can not arise because the marker is not read by the camera.

Index Terms: Augmented Reality, Introduction, Marine Ornamental Fish, Marker Based Tracking 


\section{PENDAHULUAN}

Keanekaragaman hewan di Indonesia sudah dikenal hingga mancanegara. Indonesia memiliki berbagai spesies hewan baik di darat maupun di laut (Harun \& Miratul, 2018). Keberadaan hewan laut di Indonesia saat ini semakin terancam oleh perusakan ekosistem dan perburuan hewan laut dengan barang yang tidak sebaiknya dilakukan seperti menggunakan racun sianida dan menggunakan bom cara seperti itu laut menjadi tercermar, ekosistem yang berada di laut menjadi rusak dan hewan-hewan yang berada di laut banyak yang mati.

Teknologi saat ini berkembang pesat dalam dunia pendidikan(Al Irsyadi \& Rohmah, 2017). Teknologi Augmented Reality memungkinkan anak untuk berinteraksi dengan objek 3D secara realtime dengan kenyataan(Markamah, Subiyanto, \& Murnomo, 2018). Augmented Reality memiliki perumpamaan nyata dan virtual. Augmented Reality sudah diterapkan di berbagai bidang kehidupan, salah satunya sebagai media pembelajaran untuk anak(Saurina, 2016). Pengenalan hewan laut untuk anak usia 3 tahun masih menggunakan media kertas atau gambar yang sering dijumpai pada buku anak, degan media tersebut dirasa masih kurang menarik perhatian anak dalam mengikuti pembelajaran(Al Irsyadi \& Rohmah, 2017). Sedangkan perkembangan teknologi saat ini dapat menjadi lebih efektif dalam sistem pembelajaran (Harun \& Miratul, 2018)

Salah satu contoh perkembangan teknologi Augmented Reality adalah pembelajaran dalam bentuk virtual animasi 3D (Hakim, 2018). Pemanfaatan ini akan memunculkan gambar 3D pada sebuah marker. Augmented Reality tersebut akan memunculkan objek 3D hewan yang ada di dalam laut seperti ikan hias yang memiliki warna dan corak yang beraneka sehingga dapat menarik perhatian anak-anak. Dengan Augmented Reality ini anak-anak dapat mengenal hewan-hewan yang ada di dalam laut dan dapat merangsang minat belajar dan imajinasi pada anak(Wibowo, Saputra, Amalia, \& Ulfa, 2018).

\section{METODOLOGI PENELITIAN}

\section{A. Flowchart Perancangan}

Flowchart dibuat untuk menggambarkan urutan perancangan aplikasi(Maulida, Anra, \& Pratiwi, 2018). Perancangan ini dimulai dengan tahap mempersiapkan keseluruhan aset yang" digunakan dalam proses perancangan seperti marker yang digunakan sebagai penanda objek 3D(Irfansyah, 2017). Pengumpulan data yang tertera dalam flowchart dilakukan untuk melihat perbandingan dari permasalahan yang terdapat pada penelitian sebelumnya yang kemudian digunakan menjadi rumusan masalah. Pada tahap 3D modeling dalam flowchart, akan dibuat objek 3D yang nantinya ditampilkan dalam aplikasi. Perancangan aplikasi digunakan untuk membuat sebuah hewan 3D, yang nantinya digunakan untuk memunculkan sebuah hewan 3D. Jika terjadi error selama dilakukan testing aplikasi, maka perlu dilakukan testing ulang, jika berhasil dalam testing aplikasi maka diproses (build) untuk dijadikan aplikasi android (.apk) (Atmajaya, 2017).

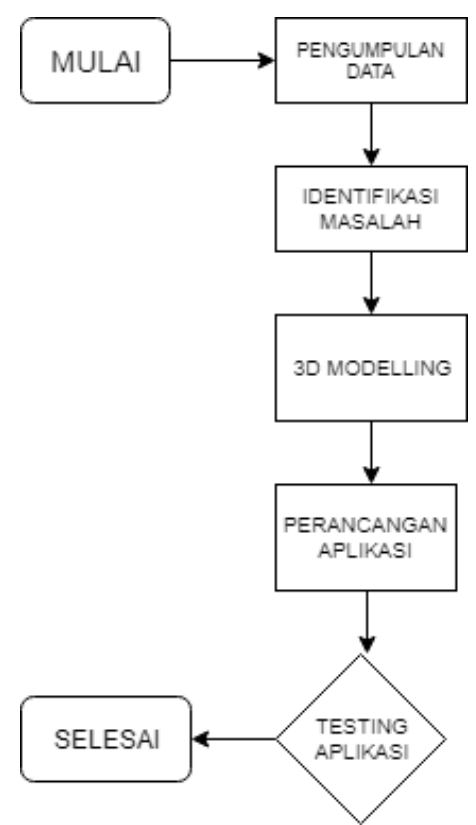

Gambar 1. Flowchart Perancangan AR

Pada gambar 1. Tahap perancangan diawali dengan pengumpulan data. Pada tahap ini dibutuhkan beberapa asset 3D yang dibuat menggunakan sketchup. Lalu Selanjutnya identifikasi masalah yaitu yang berkaitan dengan permasalahan yang terdapat pada saat membuat asset $3 \mathrm{~d}$ ataupun saat 
pembuatan AR. Selanjutnya yaitu pembuatan 3D modeling, 3D modeling ini menggunakan software Skecthup yang nantinya akan di export untuk di import pada unity. Selanjutnya tahap perancangan aplikasi, pada tahap ini setelah semua asset terlang terancang di unity saatnya AR dijadikan apk untuk nantinya bisa di jalankan pada smartphone android, agar bisa dijalankan perlu menggunakan software android studio. Selanjutnya yaitu testing aplikasi, pada tahap ini di perlukan uji coba aplikasi pada smartphone apakah aplikasi yang telah dibuat berjalan baik atau tidak.

\section{B. Marker Based Tracking}

Marker adalah suatu ilustrasi hitam dan putih persegi dengan ditandai batasan hitam tebal dan latar belakang yang berwarna putih. Marker ini merupakan penanda dalam Augmented Reality untuk mendeteksi objek yang nantinya dijadikan sebagai media marker dan biasanya hanya satu objek yang akan keluar pada marker tersebut. Dalam melakukan tahap pembuatan marker ini menggunakan software paint atau Adobe Illustrator.(Harun \& Miratul, 2018)

\section{Vuforia Engine}

Vuforia merupakan sebuah software Development Kit (SDK) pendukung Augmented Reality. Vuforia ini merupakan teknologi yang berfungsi untuk melacak gambar target dan objek 3D sederhana. Vuforia ini sangat mendukung untuk objek 2D atau 3D. Vuforia memiliki 4 modul yaitu: input, database, pelacakan dan pencocokan agar dapat menghasilkan gambar objek. Vuforia mendukung 2 platform untuk pembuatan aplikasi yaitu platform Android dan IOS.

\section{Algoritma Fast Corner Detection}

Algoritma FAST Corner Detection adalah pendeteksian pada suatu gambar yang mencari titik (insert point) atau sudut (corner) (Setiawan, Syaripudin, \& Gerhana, 2016).

$\begin{aligned} & \text { Algoritma } \\ & \text { Fast Corner Detection }\end{aligned}$
digunakan dalam vuforia untuk
mendefinisikan seberapa baik gambar yang
terdeteksi dan dibaca oleh SDK
Vuforia(Setiawan et al., 2016). Hal ini
dilakukan dalam Target Manager dan setiap

Target diupload melalui website resmi vuforia(Vitono, Nasution, \& Anra, 2016). Rating yang di dapat untuk setiap gambar yang di upload pada Target Manager ada di range 0 sampai 5 , dengan semakin tinggi nilai yang didapat untuk sebuah gambar target artinya komponen yang ada di dalam gambar semakin kuat untuk kemampuan mendeteksinya, jika nilai yang di dapat rendah artinya komponen yang ada pada gambar target itu lemah dan tidak dapat di baca oleh sistem Augmented Reality, jika mendapatkan nilai bintang 5 pada sebuah gambar target itu menunjukan bahwa gambar tersebut akurat dan mudah di baca oleh sistem Augmented Reality(Vitono et al., 2016).

Algoritma ini bekerja pada citra seperti berikut:

1. Titik $p$ pada citra dengan posisi awal(Xp,Yp), seperti pada gambar 2.(Zuli, 2018)

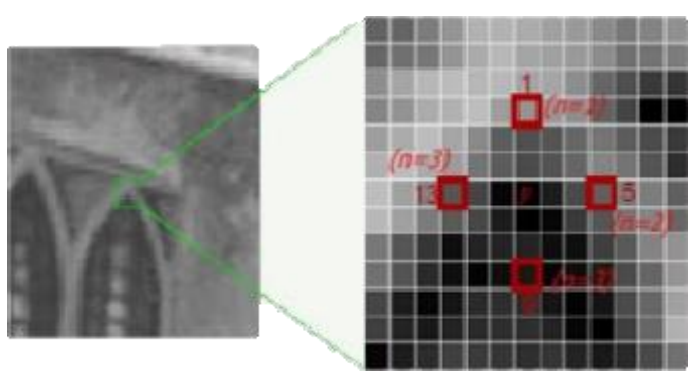

Gambar 2. Cara kerja citra dan letak posisi titik p

2. Penentuan keempat titik. Pada titik pertama yaitu $(n=1)$ yang terletak pada koordinat $(\mathrm{Xp}, \mathrm{Yp}+3)$, lalu titik yang kedua $(n=2)$ yang terletak pada koordinat $(\mathrm{Xp}+3, \mathrm{Yp})$, lalu untuk titik yang ketiga $(n=3)$ yang terletak pada koordinat (Xp,Yp-3), yang terakhir yaitu titik keempat $(\mathrm{n}=4)$ terletak pada koordinat (Xp-3,Yp).(Zuli, 2018)

3. Bandingkan intensitas pada titik pusat o dengan keempat titik yang ada di sekitar, jika terdapat paling sedikit 3 titik yang telah memenuhi syarta, maka titik pusat $\mathrm{p}$ adalah titik sudut, seperti pada rumus berikut:

$$
\begin{aligned}
& C_{p}= \\
& \left\{\begin{array}{l}
1, I_{n}<I_{p}-t \text { or } I_{n}>I_{p}+t \\
0, \text { otherwise }
\end{array}\right.
\end{aligned}
$$


Keterangan:

$\mathrm{Cp}$ : Keputusan pada titik p sebagai sudut nilai 1 menunjukan bahwa titik tersebut merupakan suatu sudut, dan nilai 0 menunjukan bahwa titik tersebut bukanlah sudut. (Zuli, 2018)

In : nilai intensitas pada piksel ke-n

Ip : nilai intensitasn pada titik $\mathrm{p}$

$\mathrm{T}$ : batas ambang nilai intensitas yang dapat di toleransi.

\section{HASIL DAN PEMBAHASAN}

\section{A. Analisis Kebutuhan Perangkat}

Dalam penelitian ini penulis membutuhkan beberapa perangkat lunak dan perangkat keras, sebagai berikut:

Tabel 1 Spesifikasi Perangkat Keras

\begin{tabular}{ll}
\hline Perangkat & Spesifikasi \\
\hline Processor & Intel I3 $8^{\text {th }}$ Gen \\
VGA & NvidiaGeforce MX130 \\
Harddisk & $1 \mathrm{~TB}$ \\
RAM & $8 \mathrm{~GB}$ \\
\hline
\end{tabular}

Tabel 2 Spesifikasi Perangkat Lunak

\begin{tabular}{c}
\hline Perangkat Lunak \\
\hline Unity 3D 2017.3 1f1 (64-bit) \\
Sketchup 2018 \\
Adobe Illustrator CC (64-bit) \\
Android Studio \\
\hline
\end{tabular}

B. 3D Modeling dan Design Marker

Dalam perancangan aplikasi ini hal yang sangat dibutuhkan yaitu design marker dan $3 \mathrm{D}$ modelingnya.

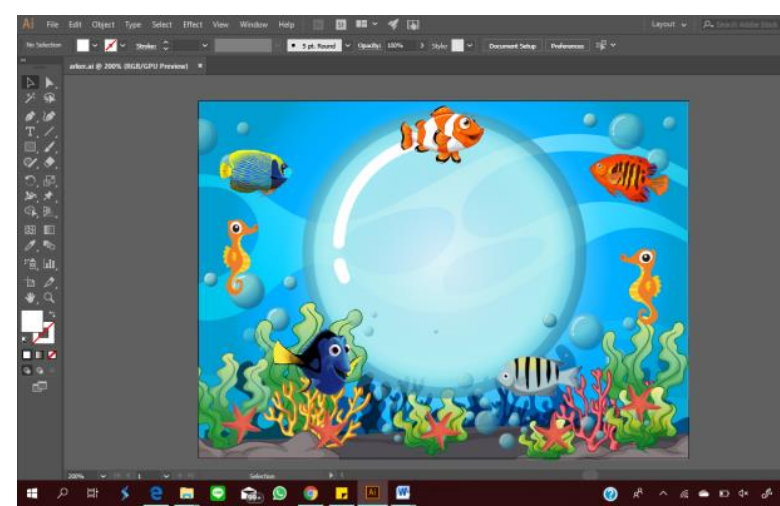

Gambar 3. Pembuatan Marker

Pada Gambar 3 ini terdapat proses pembuatan marker yang menggunakan software Adobe Illustrator CC.

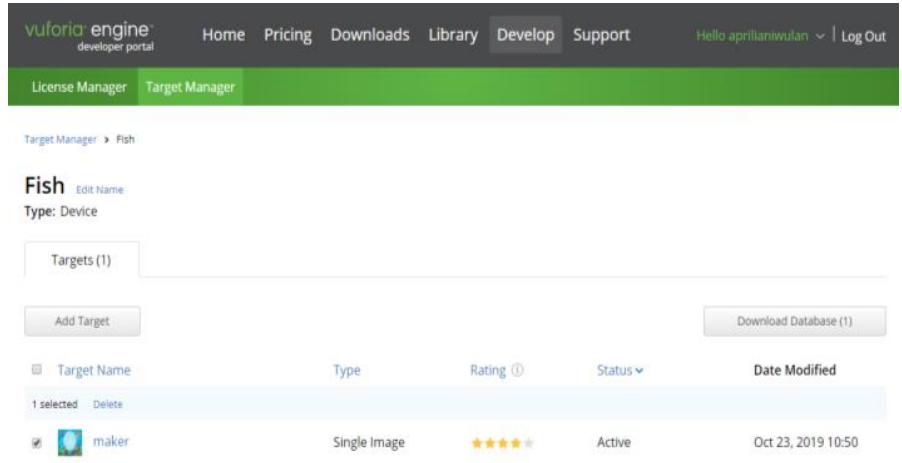

Gambar 4. Vuforia Engine

Setelah membuat design marker pada Adobe Illustrator CC selanjutnya marker tersebut diupload pada platform Vuforia Engine, pada tab Target Manager lalu pilih create database, setalah create database pilih data base tersebut lalu upload marker tersebut pada database.

Star+Fish - Sketchup Pro 2018 (18 days left in TRIAL)

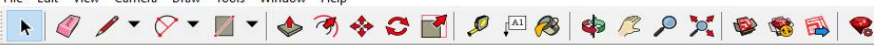

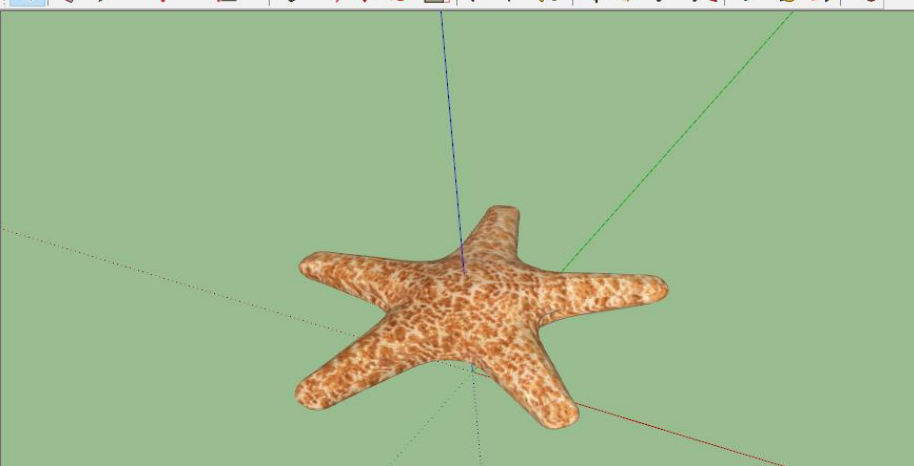

Gambar 5. 3D Modeling

Setelah membuat marker selesai lalu yang dilakukan selanjutnya yaitu membuat objek 3D melalui software sketchup 2018, setelah selesai dibuat lalu export dengan format file collada agar ketika di import pada unity bisa memunculkan tekstur yang terdapat pada objek tersebut.

\section{Desain Aplikasi}

Pembuatan Aplikasi ini di perlukan desain antar muka agar menarik, penulis membuat desain antar muka dan marker sebagai penanda untuk objek 3D, berikut desain antar muka aplikasi: 
Tabel 3 Design Aplikasi AR

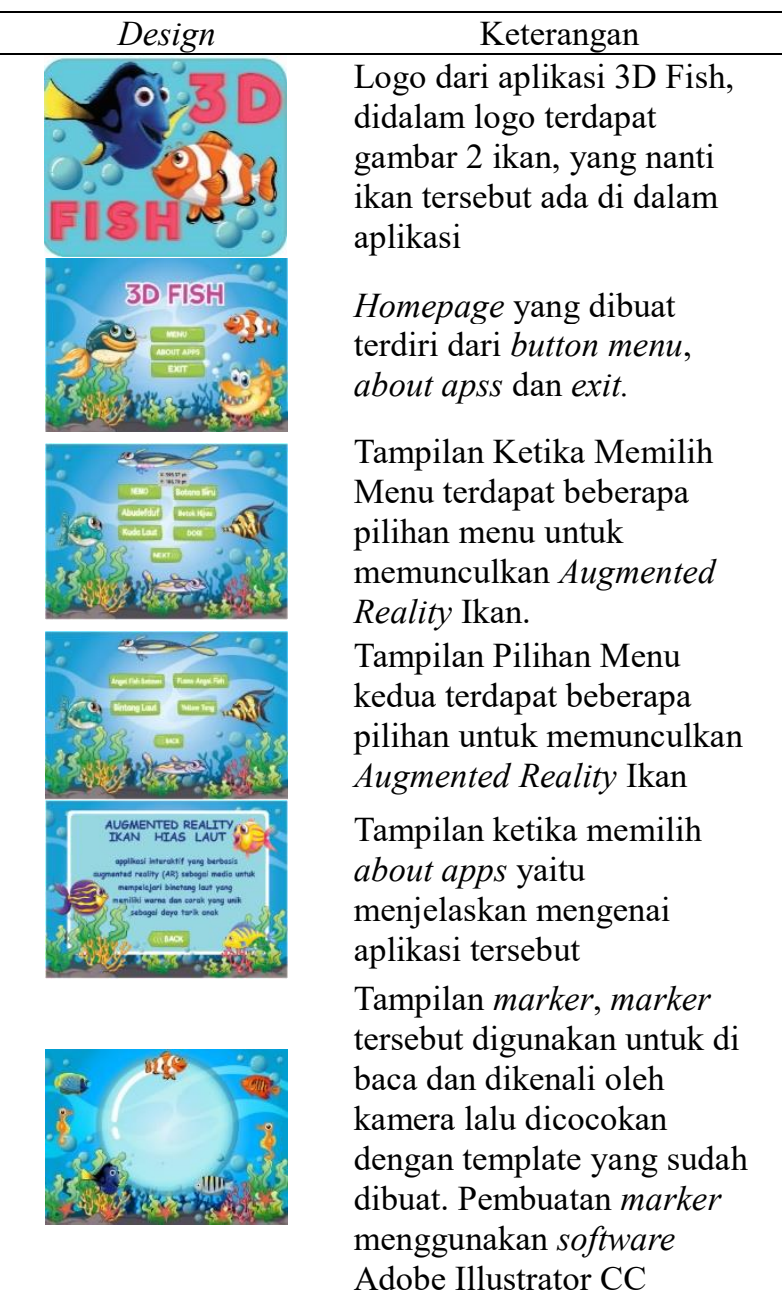

\section{Cara Menjalankan Aplikasi}

Pertama yang perlu dilakukan pengguna untuk menjalankan aplikasi yaitu proses install aplikasi. Kemudian akan diarahkan pada splash screen dari unity untuk menuju ke menu utama. Selanjutnya pengguna akan menuju homepage dengan pilihan button MENU untuk melihat menu pilihan tentang ikan. Button ABOUT APPS yaitu untuk menjelaskan maksud dari aplikasi tersebut dibuat, dan button EXIT untuk menutup aplikasi 3D Fish.

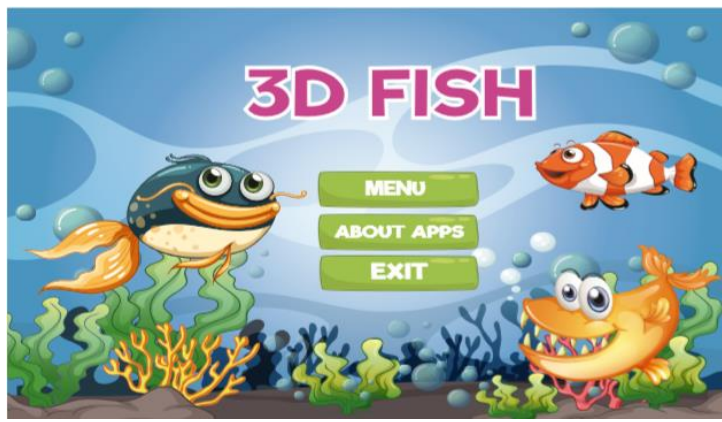

Gambar 6 Tampilan Main Menu
Pada Gambar 6 merupakan Tampilan menu utama terdapat button Menu, About Apps, dan Exit

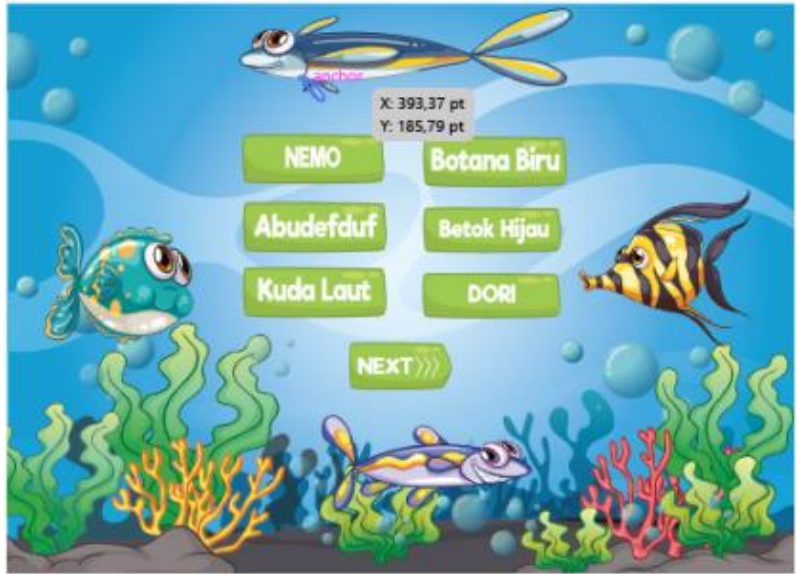

Gambar 7. Tampilan Pilihan Menu

Pada Gambar 7 merupakan Tampilan ketika membuka button menu terdapat beberapa pilihan ikan yang bisa user pilih, button next untuk ke menu selanjutnya.

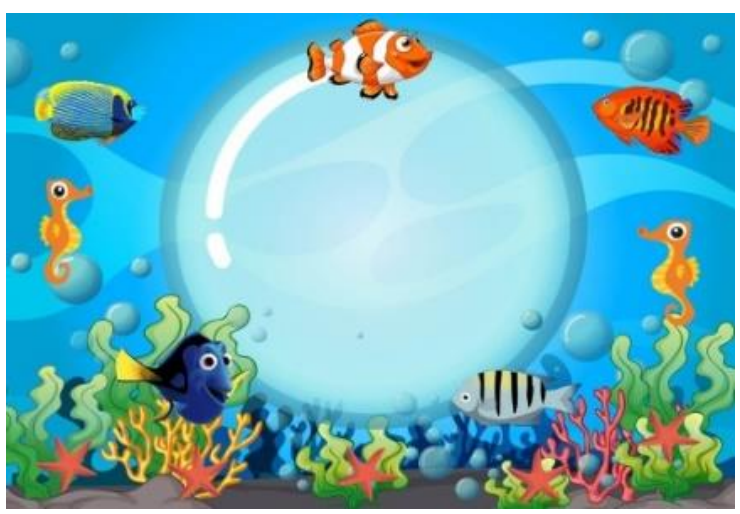

Gambar 8. Tampilan Marker

Pada Gambar 8 merupakan Tampilan marker, dimana marker tersebut berguna sebagai penanda yang nantinya akan dibaca dan dikenali oleh kamera lalu dicocokan dengan template yang sudah dibuat. Marker dibuat menggunakan software Adobe Illustrator CC.

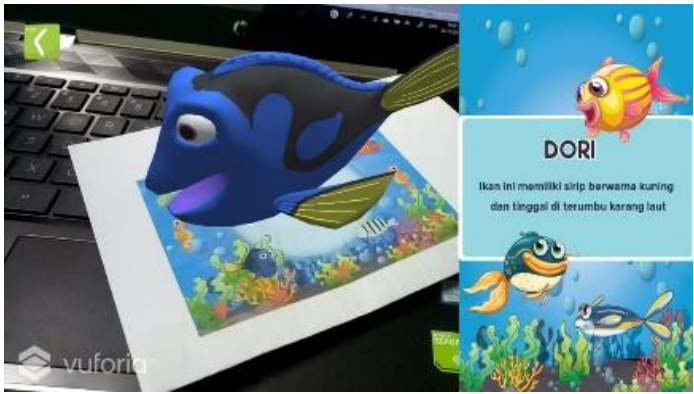

Gambar 9. Tampilan 3D Ikan Dori

Pada Gambar 9 terdapat tampilan 
Augmented Reality ikan dori. Selain memunculkan objek 3D di samping kanan layar terdapat penjelasan singkat mengenai ikan dori.

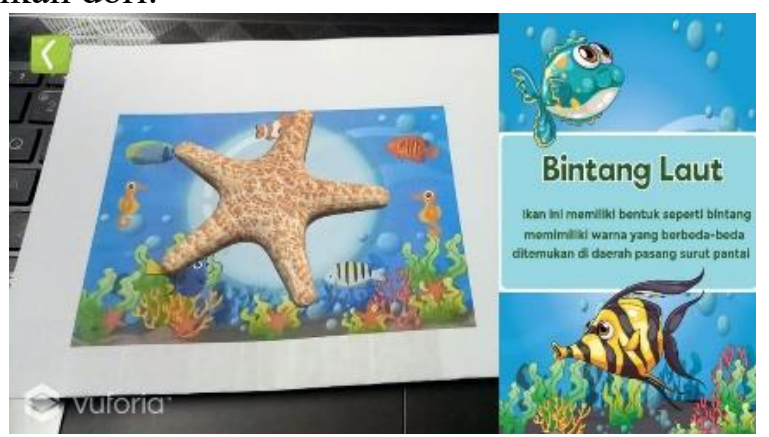

Gambar 10. Tampilan 3D Bintang Laut
Pada Gambar 10 terdapat tampilan Augmented Reality Bintang Laut. Selain memunculkan objek 3D di samping kanan layar terdapat penjelasan singkat mengenai bintang laut.

E. Pengujian Device

Pengujian dilakukan pada 3 device smartphone berbasis android dengan spesifikasi yang berbeda.

Tabel 4. Spesifikasi Smartphone

\begin{tabular}{cccc}
\hline Spesifikasi & Oppo A39 & Xiaomi 4a & Asus Zenfone Pro \\
\hline Prosessor & OctaCore & Qualcom MSM 8917 & Snapdragon 636, \\
RAM & $3 \mathrm{~GB}$ & Snapdragon 425 & 4GB \\
Ukuran Layar & 5.2 inch & 2 GB & 6 inch \\
Versi Android & Android 5.1 & Android 6.0.1 & Android Oreo 8.1 \\
\hline
\end{tabular}

F. Hasil Pengujian

Dari pengujian menggunakan Smartphone yang berbeda, terdapat hasil pengujian sebagai berikut:

Tabel 5. Hasil Pengujian Kecepatan Merespon

\begin{tabular}{lc}
\hline \multicolumn{1}{c}{ Perangkat } & Waktu Respon \\
\hline Oppo A39 & $<4$ detik \\
Xiaomi 4a & $<4$ detik \\
Asus Zenfone Pro & $<4$ detik \\
\hline
\end{tabular}

Dilakukan pengujian terhadap jarak

Hasil pengujian kecepatan merespon pada tiga smartphone memiliki hasil yang sama dan membutuhkan waktu yang sangat singkat yaitu $<4$ detik maka AR langsung timbul dengan hasil pengujian aplikasi Augmented Reality menggunakan 3 smartphone seperti pada tabel 6 . pada layar smartphone.

Tabel 6. Hasil Pengujian Jarak

\begin{tabular}{ccc}
\hline Perangkat & Jarak Minimal & Jarak Maksimal \\
\hline Oppo A39 & $\pm 12 \mathrm{~cm}$ & $\pm 127 \mathrm{~cm}$ \\
Xiaomi 4a & $\pm 13 \mathrm{~cm}$ & $\pm 129 \mathrm{~cm}$ \\
Asus Zenfone Pro & $\pm 11 \mathrm{~cm}$ & $\pm 121 \mathrm{~cm}$ \\
\hline
\end{tabular}

Tabel 7. Hasil Pengujian Intensitas Cahaya

\begin{tabular}{cccc}
\hline Intensitas Cahaya & Oppo A39 & Xiaomi 4a & Asus Zenfone Pro \\
\hline Terang & Terdeteksi & Terdeteksi & Terdeteksi \\
Remang & Lama Respon & Lama Respon & Lama Respon \\
Gelap & Tidak Terdeteksi & Tidak Terdeteksi & Tidak Terdeteksi \\
\hline
\end{tabular}

Tabel 8. Hasil Pengujian Kemiringan Sudut

\begin{tabular}{cccc}
\hline \multirow{2}{*}{ Perangkat } & \multicolumn{3}{c}{ Keterangan } \\
\cline { 2 - 3 } & $<15^{\circ}$ & $21^{\circ}-60^{\circ}$ & $61^{\circ} 90^{\circ}$ \\
\hline
\end{tabular}




\begin{tabular}{llll}
\hline Oppo A39 & Tidak Terdeteksi & Terbaca & Terbaca \\
Xiaomi 4a & Tidak Terdeteksi & Terbaca & Terbaca \\
Asus Zenfone Pro & Tidak Terdeteksi & Terbaca & Terbaca \\
\hline
\end{tabular}

\section{KESIMPULAN}

Dari pengujian sudut yang dilakukan hasil dari ketiga smartphone yaitu pada sudut $21^{\circ}$ $90^{\circ}$ dapat teraca sedangkan untuk sudut $<15^{\circ}$ AR tidak dapat timbul sebab marker tidak terbaca oleh kamera. Dari hasil pengujian intensitas cahaya yang dilakukan pada tiga smartphone yaitu ketika instesitas cahaya remang dan gelap AR tidak dapat timbul pada marker sedangkan pada cahaya terang AR dapat muncul dan terbaca oleh kamera.

Hasil dari pengujian kecepatan respon pada AR membutuhkan waktu rata-rata $<4$ detik hingga tampil pada layer. Aplikasi ini dapat dijalankan pada smartphone android dengan operasi sistem minimal 5.1 (lollipop)

\section{REFERENSI}

[1] Al Irsyadi, F. Y., \& Rohmah, A. N. (2017). Pemanfaatan Augmented Reality Untuk Game Edukasi Bagi Anak Autis Tingkat Sekolah Dasar Di Rumah Pintar Salatiga. Simetris: Jurnal Teknik Mesin, Elektro Dan Ilmu Komputer, 8(1), 9198.

https://doi.org/10.24176/simet.v8i1.837

[2]Atmajaya, D. (2017). Implementasi Augmented Reality untuk Pembelajaran Interaktif. Jurnal Ilmiah ILKOM UMI Makassar, 9, 227-232.

[3]Hakim, L. (2018). Pengembangan Media Pembelajaran Pai Berbasis Augmented Reality. Lentera Pendidikan: Jurnal Ilmu Tarbiyah Dan Keguruan, 21(1), 59-72.

https://doi.org/10.24252/lp.2018v21n1i6

[4]Harun, M., \& Miratul, K. M. (2018). Aplikasi Pengenalan Hewan Lindung Menggunakan Augmented Reality dengan Metode Marker Based Tracking. 1(1), 34-43.

[5]Irfansyah, J. (2017). Media Pembelajaran Pengenalan Hewan Untuk Siswa Sekolah Dasar Menggunakan Augmented Reality Berbasis Android. JIEET (Journal Information Engineering and Educational Technology), 01, 9.

[6]Markamah, N., Subiyanto, \& Murnomo, A. (2018). The Effectiveness of Augmented Reality App to Improve Students Achievement in Learning
Introduction to Animals. Journal of Education and Learning (EduLearn), Vol.12, No, 651 657.

[7]Maulida, N., Anra, H., \& Pratiwi, H. S. (2018). Aplikasi Pembelajaran Interaktif Pengenalan Hewan pada Anak Usia Dini. Jurnal Sistem Dan Teknologi Informasi (JustIN), 6(1), 26. https://doi.org/10.26418/justin.v6i1.237 26

[8]Saurina, N. (2016). Pengembangan Media Pembelajaran Untuk Anak Usia Dini Menggunakan Augmented Reality. Jurnal IPTEK, 20(1), 95. https://doi.org/10.31284/j.iptek.2016.v2 0 il. 27

[9]Setiawan, E., Syaripudin, U., \& Gerhana, Y. A. (2016). Implementasi Teknologi Augmented Reality pada Buku Panduan Wudhu Berbasis Mobile Android. Jurnal Online Informatika, 1(1), 28. https://doi.org/10.15575/join.v1i1.8

[10]Vitono, H., Nasution, H., \& Anra, H. (2016). Implementasi Markerless Augmented Reality Sebagai Media Informasi Koleksi Museum Berbasis Android (Studi Kasus: Museum Kalimantan Barat). Universitas Tanjungpura Pontianak, 2(4), 239-245.

[11]Wibowo, D. W., Saputra, P. Y., Amalia, E. L., \& Ulfa, F. (2018). Penerapan Library AR.JS untuk Pembuatan Augmented Reality Sebagai Media Pembelajaran Pengenalan Hewan. SMARTICS Journal, 4(2), 52-55. https://doi.org/10.21067/smartics.v4i2.3 185

[12]Zuli, F. (2018). Rancang Bangun Augmented Dan Virtual Reality Menggunakan Algoritma Fast Sebagai Media Informasi 3D Di Universitas Satya Negara Indonesia. Jurnal Algoritma, Logika Dan Komputasi, 1(2), 94-104. https://doi.org/10.30813/jalu.v1i2.1373 
Wulandari, Apriliani (2019) 